\title{
Study of Core Competence of Logistics Cluster: The Integration and the Extension of Value Chain
}

\author{
Shuang Wang \\ Department of Logistics Management, Tianjin Coastal Polytechnic, Tianjin, China \\ Email: Shuang.w@foxmail.com
}

Received 12 November 2014; accepted 5 January 2015; published 21 January 2015

Copyright (C) 2015 by author and Scientific Research Publishing Inc.

This work is licensed under the Creative Commons Attribution International License (CC BY). http://creativecommons.org/licenses/by/4.0/

c) (i) Open Access

\begin{abstract}
This paper focuses on the study of core competence of logistics cluster with the solution in two levels: one is the integration of supply chain, and the other point is the extension of value chain; both of them are based on the measurement of agglomeration level of logistics cluster and association level of cluster external resources. Hereby the MAEI model is proposed which is used to evaluate the agglomeration and association level as well as to enhance the core competence of logistics cluster by the solution of integration and extension of value chain.
\end{abstract}

\section{Keywords}

Logistics Cluster, Value Chain, Measurement of Industrial Cluster Level

\section{Introduction and Problem Presentation}

Logistics clusters as per definition are geographically concentrated sets of logistics-related business activities, which have already become one of the most important regional development strategies. The enterprises and business functions which are involved in such cluster can share logistics expertise and know-how as well as enjoy cost and service benefits. Particularly for the regions being of sound maritime location and hinterland networks, enhancing core competence of logistics cluster should be an authentic method to settle the problems, such as:

- how to provide the systematic services and acquire adequate benefits from the international port and maritime markets;

- how to make better positive feedback loop by developing the cluster cooperation;

- how to enhance the core competence of holistic region as well as the enterprises evolved in the clusters;

- how to acquire the sustainable driving forces for competitive advantages. 
Rather than conventional regional economy assumption, it is much more significant to foster the core competence of logistics cluster to face the challenge of the global market. It obviously provides numerous competent advantages for the regional development and cluster participants involved.

Like everything has its presupposition, a simplistic low level cluster does not make too much sense for contributing the economy growth or business development. Those advantages above-mentioned of logistics cluster should be based on an efficient and coordinate operation system; it may not be an intensive multi-contracts relationship, nevertheless it should be of high level integrated operation in agglomeration degree, coordination efficiency and external effect.

Logistics cluster, like a complex structured ecological system, comprises of the logistics-intensive services providers composing the backbone of cluster, the assistant service groups providing capital and information flow, as well as cluster governance authorities in charge of the management and collaboration within the cluster. Since the multiple actors have involved in the cluster, it certainly needs to form many strengths, such as more mutual trust amongst, wider coherent knowledge and information adoption, easier business cooperation and collaboration, and more employment opportunities. However because of the dynamics of forming the cluster, the challenge of global maritime market fluctuation and non-cooperative game factors, an effective evaluation system of the logistics cluster is necessary. Therefore, it is necessary and of positive significance to develop the evaluation index system to evaluate the agglomeration degree, coordination efficiency and external effect of the logistics cluster; thereupon it can provide more scientific solutions for developing the core competence of the logistics cluster according to the evaluating results.

On the other hand, logistics cluster widely agglomerate resources involved; hence the challenges should be how to provide the capability of value-added operations associated with the global value chain and how to make it possible that the participants share the benefits of lower cost and resource collaboration for creative value activities. Nevertheless, a sound evaluation index system can provide scientific basis and data for answering the following questions:

- What is the status of internal and external relations of the logistics cluster? Are these relationships in a high level of relevance and dependency? That is the agglomeration of the cluster;

- What is the status of the corporation amongst the participants? Is it more smoothly and efficiently running due to the cluster integration? That is the coordination efficiency;

- What is the status of the external connections linked with the logistics cluster? How much external recourse can be integrated by the logistics cluster? That is the external effect.

Accordingly, hereby the research is concentrated to establish a set of evaluation index system to answer the above questions and moreover to provide solutions being of positive scientific value to form core competence of logistics cluster.

\section{Literature Review}

The concept of cluster was firstly pointed out by Michael Porter [1] of the Harvard Business School (1990). He defined the cluster as a geographic concentration of interconnected businesses, suppliers, and associated institutions in a particular field. In the following research, Michael Porter claims that clusters have the potential to affect competition in three ways:

- by increasing the productivity of the companies in the cluster;

- by driving innovation in the field;

and

- by stimulating new businesses in the field (1998) [2].

Reviewed the relevant literatures, most of the research are concentrated on the industry cluster, as to study the reason and mechanism of establishment of industry cluster, i.e. Kaugaman [3], Szilasi and Kalscu [4] are focused in their study on the automobile industry. Some scholars adopted system analysis approaches analyzing the complexity of the cluster system (Wang, Wei et al., 2007) [5] and the innovation activities of logistics cluster (Mu Jing et al., 2013) [6].

In recent years, there are many significant research achievements in logistics cluster. Yossi Sheffi pointed out the view that logistics intensive cluster creates the global competitiveness and regional growth [7]. In his research thesis and further he argues the logistics cluster delivering value and driving growth [8]. With the former research achievements it has already answered the questions of what it is and how it establishes and be evaluated. 
Therefore, the research directions in the future should be concentrated on how to develop its competence, how to improve integration and advantages and resources, etc.

\section{Targets of Building Core Competence of Logistics Cluster}

Therefore, based on the study of relevant literatures and practical requirements, this research proposed to focus on four aspects study of core competence of logistics cluster:

- measurement of agglomeration level of logistics cluster and association level of cluster external resources by applying the methodologies of Hirschman-Herfindahl index, entropy index and space Gini coefficient. The above mentioned measurement could provide the basic data for identifying the status of Logistics Cluster and making policy decision;

- the key influencing factors in successfully developing logistics clusters; hence build the appropriate models of two important relationships amongst Logistics Clusters as a whole, with external environment and internal system;

- the obstacles of internal resource integration within the cluster, then, points out the integrated path of value chain as network structure, multivariate extension, coherent information and knowledge sharing and proper government support which is in the form of infrastructures investment, as well as regulation or policy with sustainable holistic thinking;

- the methods of widening the value chain by optimal allocation of resources, lower transaction costs, extending the resource leverage to acquire external value, as well as the operation with internet and financing thinking to get more space and time value.

\section{Methodology-MAEI Model}

Based on the above analysis, here we propose a model of MAEI for fostering the core competence of logistics cluster.

On the one hand, it clearly elaborates the procedures how to evaluate and more over to enhance the core competence of logistics cluster. The name MAEI stands for four steps, they are, measurement, analysis, extension and integration as the following elaboration in Table 1.

On the other hand it proposes the key factors during the course of integrating and extension the value chain.

\section{A) Measurement of agglomeration level of logistics cluster}

As the achievements already obtained by many experts in the field of industrial cluster, there are several methods to evaluate the agglomeration level amongst industrial cluster. According to the targets of building core competence of logistics cluster, here within be involved method should answer three questions as following:

- What is the agglomeration degree of logistics industrial in holistic level?

- What is the orderly degree of different scale enterprises involved in the logistics cluster?

- What is the balance degree of spatial distribution of logistics cluster?

\section{Table 1. Procedures of MAEI model.}

\begin{tabular}{|c|c|c|c|}
\hline Procedure & Description & Methodology & Outputs \\
\hline \multirow{3}{*}{ Measurement } & \multirow{3}{*}{$\begin{array}{l}\text { Measurement of } \\
\text { agglomeration } \\
\text { level of logistics } \\
\text { cluster }\end{array}$} & Hirschman-Herfindahl index, HHI & $\begin{array}{l}\text { Measure of the logistics industrial agglomeration } \\
\text { degree on holistic point of view }\end{array}$ \\
\hline & & Entropy index & $\begin{array}{l}\text { Measure of the orderly degree of different scale } \\
\text { enterprises involved in the logistics cluster }\end{array}$ \\
\hline & & Space Gini coefficient & The balance of spatial distribution of logistics cluster \\
\hline \multirow{3}{*}{ Analysis } & \multirow{3}{*}{$\begin{array}{c}\text { Analysis of } \\
\text { association level } \\
\text { of cluster external } \\
\text { resources }\end{array}$} & Resource leverage analysis & $\begin{array}{l}\text { Torque and lever of dynamical resource } \\
\text { within the logistics cluster }\end{array}$ \\
\hline & & Data Envelopment Analysis, DEA & $\begin{array}{l}\text { Correlation between ecological system of } \\
\text { logistics cluster and external resources }\end{array}$ \\
\hline & & PEST Analysis & $\begin{array}{l}\text { Identifying the external environments by analysis } \\
\text { of political system, economic, social and technology }\end{array}$ \\
\hline $\begin{array}{l}\text { Extension and } \\
\text { integration }\end{array}$ & $\begin{array}{l}\text { Extension of } \\
\text { value chain }\end{array}$ & Value chain strategy matrix & $\begin{array}{l}\text { Strategies of value chain extension in different } \\
\text { agglomeration and correlation levels }\end{array}$ \\
\hline
\end{tabular}


Therefore, it should adopt methods of measurement in three levels that work best for answering the above questions.

First, Hirschman-Herfindahl index, HHI [9].

Originally, it is a measure of the size of firms in relation to the industry and an indicator of the amount of competition among them. The result is proportional to the average market share, weighted by market share. As such, it can range from 0 to 1.0, moving from a huge number of very small firms to a single monopolistic enterprise. Hereby, it used to measure the agglomeration degree particularly in logistics industrial on holistic point of view. The formula of HHI could be definite as follows:

$$
\mathrm{HHI}=\sum_{i=1}^{N}\left(X_{i} / X\right)^{2}=\sum_{i=1}^{N} S_{i}^{2}
$$

where $S_{i}$ is the market share of firm $i$ in the market and $N$ is the number of firms. Thus, in a market with two firms that each have 50 percent market share, the Herfindahl index equals $0.50^{2}+0.50^{2}=1 / 2$. As such, it can have following rules:

a HHI index below 0.01 (or 100) indicates a highly competitive index;

a HHI index below 0.15 (or 1500) indicates an unconcentrated index;

a HHI index between 0.15 to 0.25 (or 1500 to 2500) indicates moderate concentration;

a HHI index above 0.25 (above 2500) indicates high concentration

Second, entropy index, E index.

E index, to some extent, is familiar with HHI. However, because it adopts the reciprocal and logarithm to weight the market share, therefore, it can be better use to measure the orderly degree of different scale enterprises involved in the logistics cluster as the following formula:

$$
\mathrm{EI}=\sum_{i=1}^{N} S_{i} \log \left(1 / S_{i}\right)
$$

where $S_{i}$ is the market share of firm $i$ in the market and $N$ is the number of firms.

Third, space Gini coefficient [10].

Due to Gini coefficient can be used to compare or rank distributions (e.g. probability distribution, frequency distribution or size distribution) can be used as a market concentration criterion. Hereby, the space Gini coefficient is used to weight the balance of spatial distribution of logistics cluster as the following formula:

$$
\mathrm{G}=\sum_{i=1}^{N}\left(S_{i}-X_{i}\right)^{2}
$$

where $S_{i}$ is the market share index of relevant industrial area $i$ (output, employment, sales, total assets) accounted in the national industrial amount $X_{i}$ is the market share index of area $i$ (output, employment, sales, and total assets) accounted in the national amount. And $N$ is the number of areas.

As to the inherent defect of space Gini coefficient, it ignores the negative effects of large scale enterprises to the result. Therefore, $G$ index should be applied with other two indexes above mentioned.

\section{B) Analysis of association level of cluster external resources}

To analyze the association level of cluster external resources is the foundation to indentify the chances of integrating external resources or expanding the correlations alongside the value chain. To make it better work of analysis or evaluation of such association should on three levels:

- Gravity of cluster kernel, which is the inherent power to generate external effect.

As coming from the mechanical principle of Archimedes's law, resource leverage analysis is used to measure the torque and lever of dynamical resource within the logistics cluster, and finally find out the core resources as so called gravity of cluster kernel which can prolong the leverage in order to pry more external resources as the formula describing:

$$
F 1 \cdot L 1=F 2 \cdot L 2
$$

There are two results of prolonging the $L 1$, which is, either decreasing the $F 1$ which means the input of the system declined, or increasing one of $F 2$ and $L 2$ and eventually overall output of the system.

Most of the time the energy that can prolong $L 1$ within logistics cluster should be offered though innovating the service contents and expanding the service chains. 
- Correlation efficient between internal and external of cluster, which is the channel transmitting the energy of outward integration;

Data envelopment analysis, DEA methodology [11], efficiency is defined as a ratio of weighted sum of outputs to a weighted sum of inputs, where the weights structure is calculated by means of mathematical programming and constant returns to scale (CRS) are assumed.

As such, it is expanded to be used as a ratio of weighted sum of external resource respond to a weighted sum of internal cluster resource and activities, where the ratio reflects the correlation efficient between internal and external of cluster.

- Evaluation of external environment comprising of political system, economic, social and technology, which is provide the possibility and emphasis of external integration and extension.

It is the PEST Analysis used to identifying external environments by analysis of political system, economic, social and technology.

\section{C) Extension and integration of value chain}

The concentration of firms in the same industry, with their similar needs and concerns, gives natural rise to joint activities. These include government lobbying, joint cluster development and joint activities such as procurement.

Clusters include, by and large, people with similar backgrounds, language, culture, religion and customs. Thus, it is easier to develop trust, among organizations and people, leading to lower transactions costs among firms whether they are trading partners or horizontal collaborators/competitors. In most cases this trust is based on relationships forged outside the work environment [12].

Large scale companies have their own shortcomings: they are slow to make decisions, they are bureaucratic, and they are risk-averse [13]. Consequently, a cluster may be an optimal organizational structure, balancing flexibility and fast decision making on the one hand with the reach and resource availability on the other. In Porter's words "A cluster allows each member to benefit as if it had greater scale or as if it had joined with others formally—without requiring it to sacrifice its flexibility” [14].

The focus of extension of value chain is on a particular type of cluster-a cluster of firms with logistics-intensive operations. This includes mainly three types of companies:

- logistics services providers,

- companies with logistics-intensive operations, and

- the logistics operations of industrial firms.

A good way to extend the value chain is to extend the recourse leverage by make use of cluster aggregation resources [15].

Base on all above analysis, hereby we propose the value chain strategy matrix as descriptions in Chart 1 , which is definite the strategies of value chain extension in different agglomeration and correlation levels. Moreover, the data and ratio are provided by above formulas in the first two steps.

As the description in Chart 1, there are four types of value chain extension strategy:

\section{- Concentration type}

This type of logistics cluster generally means it is of high agglomeration level but limited correlations with external resources.

So the extension strategy of such type of cluster should focus on three aspects:

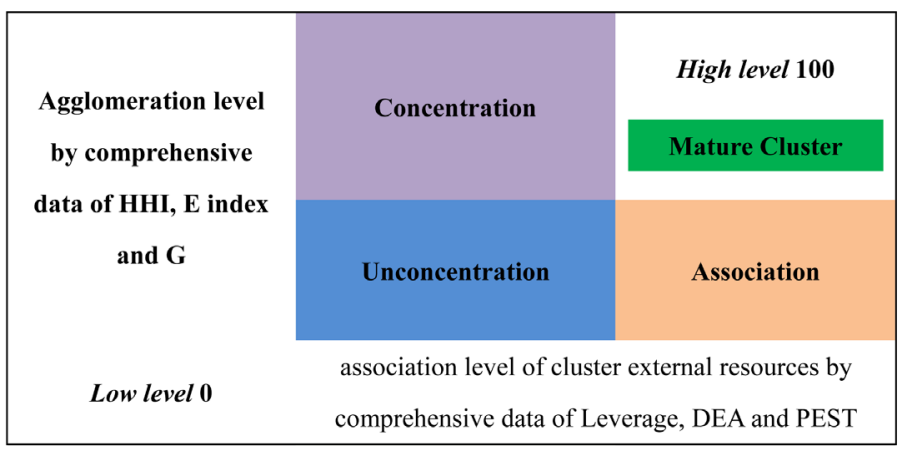

Chart 1. Value chain strategy matrix of logistics cluster. 
First, prolong the internal leverage by innovate the service contents or expand the service chain within cluster; to enhance the internal connection amongst participants by complementary advantages, e.g. provide more comprehensive logistics service through the way of alliance operation.

Second, enhance the correlation efficient between internal participants and external potential resource by external environment identification, e.g. financial cooperation opportunity, joint venture either in a valuable project or in sharing regional logistics service resource.

Third, indentify the extension opportunity in external environment by analysis of political system, economic, social and technology beyond involved logistics cluster, e.g. an positive policy, tendency of consumption structure, innovation of industrial structure, which both might provide new chance to enhance the correlation with external resource.

\section{- Unconcentration type}

This type of logistics cluster is the weakest cluster, even might not be recognized as a sort of logistics cluster. Therefore, the strategy of such cluster should be to build the concentration by efficiently organizing the participants and resource within the cluster to increase the agglomeration level amongst logistics cluster.

\section{- Association type}

This type of logistics cluster is also weaker than the first one, but the advantage of this type of cluster is better association with external resources, which may become the leverage pry the internal development and enhance cooperation within the logistics cluster.

Therefore, the strategy of such cluster is to emphasize the internal cooperation, foster logistics alliance, establish public infrastructure, share logistic information and increase the agglomeration level within logistics cluster. It is both dangerous and prospective to develop this kind of cluster. Because, it may forward to positive direction by enhancing the agglomeration level and form a high quality logistics cluster, whereas it may also forward to the negative direction if it doesn't integrate the internal participants efficiently during the course of better connection with external environment, i.e. decrease the competency in external market and possible chances of cooperation beyond the cluster.

\section{- Mature cluster type}

This is the most ideal model of logistics cluster, mature development prepared to extension by any means. It shows the cluster which is of great core competence has already formed a high level of agglomeration that is also involving in the balanced, orderly developing process. Meanwhile, it also means this cluster has better association with external resources in better external environment.

Therefore, the strategy of such type is to give consideration of both balance and efficient and of both integration and extension. That is, as the same time of keeping balance of agglomeration level within the logistics cluster, focus on the efficient of association with external environment. At the same time of integrating the external business with cross cluster participants, extension the supply chain which has been maturely associated within the logistics cluster. Meanwhile, control the developing course should be another challenge at this stage.

\section{Discussion and Conclusions}

As a conclusion, this paper provides a framework for evaluating the agglomeration of logistics cluster by measuring the concentration degree in three different levels and analyzing the association between logistics cluster and external resources. Meanwhile, it also proposes the value chain strategy as the solution of fostering the core competence of logistics cluster by extension and integration of the internal and external resources of value chain. The paper hereby focuses on three aspects of core competence of logistics cluster and forms initial model of evaluation:

- First, paper analyzes the key influencing factors to the agglomeration of logistics clusters based on the former relevant research, hence building a comprehensive model and possibly answering the following questions:

1. What is the agglomeration degree of logistics industrial in holistic level?

2. What is the orderly degree of different scale enterprises involved in the logistics cluster?

3. What is the balance degree of spatial distribution of logistics cluster?

- Second, it analyzes the obstacles of internal resource integration within the cluster, as well as the factors affecting the operating efficiency of logistics cluster even including coherent information, knowledge sharing and proper government support which is in the form of infrastructures investment, as well as regulation or policy with sustainable holistic thinking, in order to compensate the index system with the function of effi- 
ciency evaluation within the logistics cluster.

- Third, this research argues the important relationships of logistics clusters as a whole, between external environment and internal systems; hence it will widen the evaluating factors by external effects to evaluate the capability of logistics cluster in extending the resource leverage to acquire external value, as well as the operation with Internet and financing thinking to get more space and time value.

\section{References}

[1] Porter, M. (1990) The Competitive Advantage of Nations. Free Press, New York.

[2] Porter, M. (1998) Clusters and the New Economics of Competition. Harvard Business Review, Harvard.

[3] Kaugaman, A. (1991) Increasing Return and Economic Geography. Journal of Political Economy, 3, 16-20.

[4] Szilasi, I. and Kalscu, Z. (2003) Cases of Hungarian Cluster Development.

[5] Wang, W., et al. (2007) Logistics Industrial Cluster Based on Complex System Theory. International Conference on Transportation Engineering, 1984-1990.

[6] Mu, J. (2013) Logistics Cluster Service Innovation Behavior. Nankai University Press, Tianjin.

[7] Sheffi, Y. (2013) Logistics Intensive Clusters: Global Competitiveness and Regional Growth. In: Bookbinder, J., Ed., Handbook of Global Logistics, Springer Science + Business Media, New York, 463-500. http://dx.doi.org/10.1007/978-1-4419-6132-7_19

[8] Sheffi, Y. (2012) Logistics Clusters: Delivering Value and Driving Growth. MIT Press, Cambridge.

[9] The United States Dpartment of Justice (2012) Herfindahl-Hirschman Index.

[10] Curry, B. and George, K.D. (1983) Industrial Concentration: A Survey. Journal of Industrial Economics, 31, $203-255$. http://dx.doi.org/10.2307/2097885

[11] Banker, R.D., Charnes, R.F. and Cooper, W.W. (1984) Some Models for Estimating Technical and Scale Inefficiencies in Data Envelopment Analysis. Management Science, 30, 1078-1092. http://dx.doi.org/10.1287/mnsc.30.9.1078

[12] Starner, R. (2004) Transportation Makes It Five for Five. http://www.siteselection.com/issues/2004/mar/p190/

[13] Hallock, T. (2004) The Future of Logistics. Business Facilities Magazine, March 2004, L-1-2.

[14] Kuei, C.H., Madu, C.N. and Lin, C. (2008) Implementing Supply Chain Quality Management. Total Quality Management \& Business Excellence, 19, 1127-1141. http://dx.doi.org/10.1080/14783360802323511

[15] Molina-Morales, F.X. and Martinez-Fernandez, M.T. (2010) Social Networks: Effects of Social Capital on Firm Innovation. Journal of Small Business Management, 48, 258-279. http://dx.doi.org/10.1111/j.1540-627X.2010.00294.X 
Scientific Research Publishing (SCIRP) is one of the largest Open Access journal publishers. It is currently publishing more than 200 open access, online, peer-reviewed journals covering a wide range of academic disciplines. SCIRP serves the worldwide academic communities and contributes to the progress and application of science with its publication.

Other selected journals from SCIRP are listed as below. Submit your manuscript to us via either submit@scirp.org or Online Submission Portal.
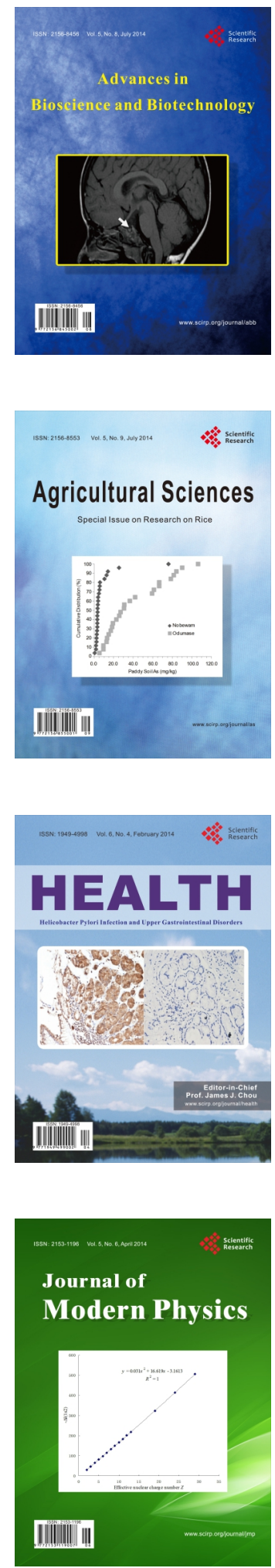
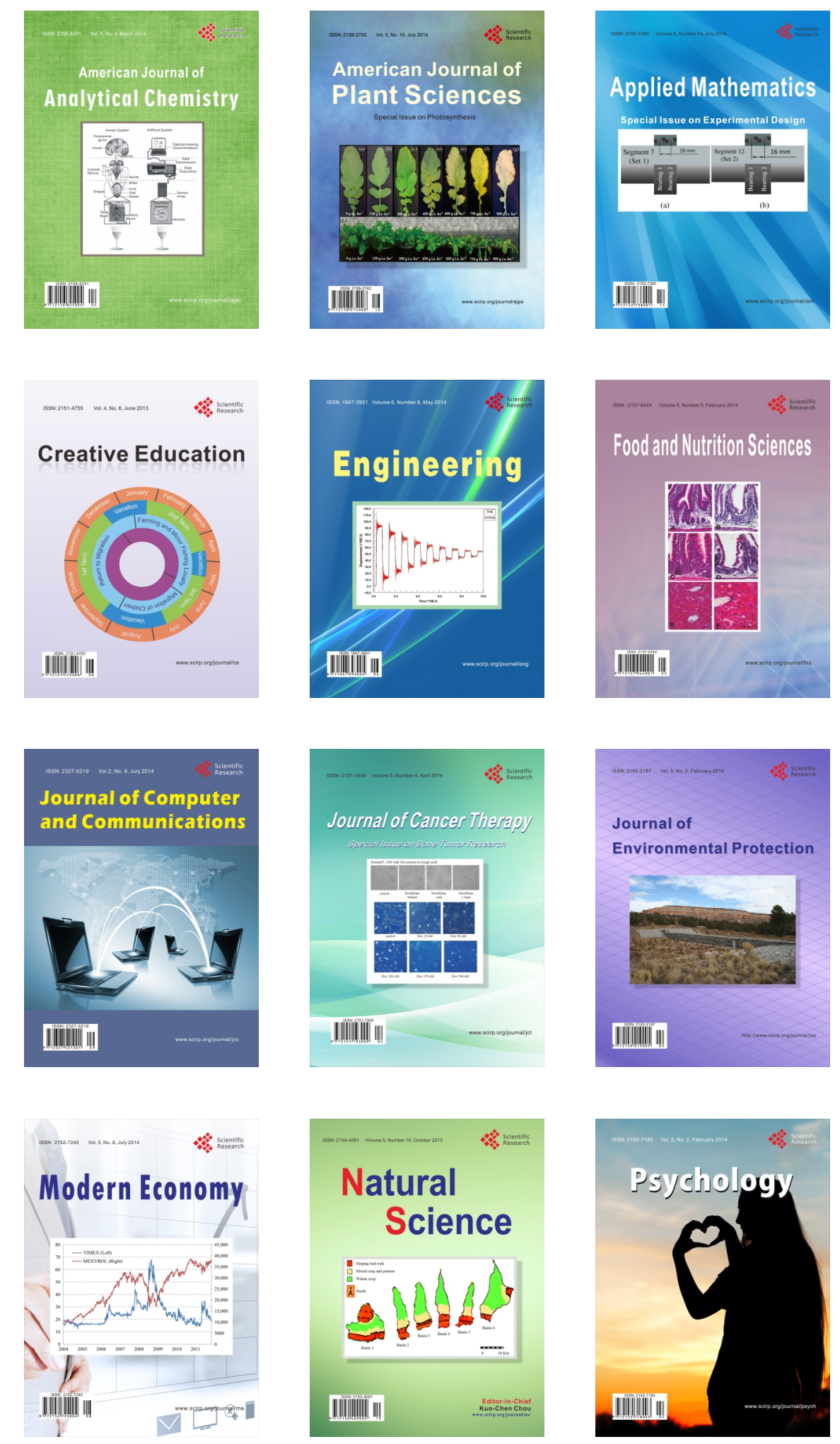